\title{
UM MÉDICO ITALIANO PARA A ESCOLA REPUBLICANA PAULISTA: A PEDAGOGIA CIENTÍFICA NAS ESCOLAS NORMAIS BRASILEIRAS
}

\author{
Maria Cristina Menezes \\ CIVILIS/FE/UNICAMP \\ menezes.mariacristina@gmail.com \\ Maria de Lourdes Pinheiro \\ CIVILIS/FE/UNICAMP \\ pinheiro.lou@gmail.com
}

\begin{abstract}
RESUMO
Dois livros, da biblioteca histórica da antiga Escola Normal de Campinas, chamaram a atenção por trazerem ambos o nome do Dr. Ugo Pizzoli, médico italiano que em 1914 ministrou o Curso de Technica Psychologica no Gabinete de Psychologia e Anthropologia Pedagógica annexo à Escola Normal de São Paulo. Estes volumes, seguidos de vários outros títulos, representam período em que predominou a pedagogia científica que se articulava à psicologia e à antropologia. O trabalho busca trazer práticas e personagens que se destacaram no cenário brasileiro por essa pedagogia que via a escola como laboratório de investigação científica e na qual o aluno deveria ser submetido a exames físicos e psíquicos.
\end{abstract}

Palavras-chave: Pedagogia científica. Escolas normais. Manuais de ensino.

\section{AN ITALIAN PHYSICIAN FOR THE PAULISTA REPUBLICAN SCHOOL: SCIENTIFIC PEDAGOGY IN BRAZILIAN NORMAL SCHOOLS}

\begin{abstract}
Two books, from the historical library of the former Normal School of Campinas, drew attention for bringing both the name of Dr. Ugo Pizzoli, an Italian physician who in 1914 taught the Course of Technica Psychologica in the Office of Psychology and Pedagogical Anthropology next to the Normal School of Sao Paulo. These volumes, followed by several other titles, represent a period in which scientific pedagogy dominated the psychology and anthropology. The work seeks to bring practices and characters that stood out in the Brazilian scenario for this pedagogy that saw the school as a scientific research laboratory and in which the student should be submitted to physical and psychic exams.
\end{abstract}

Keywords: Scientific pedagogical. Normal schools. School manuals.

\section{UN MÉDICO ITALIANO PARA LA ESCUELA REPUBLICANA PAULISTA: LA PEDAGOGIA CIENTIFICA EN LAS ESCUELAS NORMALES EN BRASIL}

\section{RESUMEN}

Dos libros, en la biblioteca histórica de la antigua Escuela Normal de Campinas, llamaron la atención por llevar el nombre del Dr. Ugo Pizzoli, médico italiano que en 1914 dio el curso Technica Psychologica en el Gabinete de Psychologia y Antropología pedagógica de la Escuela Normal de São Paulo. Estos volúmenes, seguidos por varios otros títulos, representan un periodo en el que predominaba la pedagogía científica que se vinculó a la psicología y la 
antropología. El trabajo busca traer prácticas y personajes que se destacaron en el escenario brasileño para esta pedagogía que vio la escuela como un laboratorio de investigación científica y en la que el estudiante debe someterse a exámenes físicos y psicológicos.

Palabras clave: Pedagogía científica. Escuelas normales. Manuales escolares.

\section{UN MEDECIN ITALIEN POUR L'ECOLE REPUBLICAINE PAULISTA: LA PEDAGOGIE SCIENTIFIQUE DANS LES ECOLES NORMALES BRÉSILIENNES}

\section{RÉSUMÉ}

Deux livres de la bibliothèque historique de l'ancienne École Normale de Campinas, ont pris notre attention par le nom de l'auteur, Dr Ugo Pizzoli, médecin italien qui a donné le cours de Technica Psychologica en 1914 dans le cabinet de Psychologie et AntropologiePedagógique de 1' École Normale de São Paulo. Ces volumes, suivis par d'autres titres, représentent une période qui a dominé la pédagogie scientifique liée à la psychologie et l'anthropologie. Cet article montre les pratiqueset les personnages qui se sont démarqués dans la scène brésilienne dans cette pédagogie qui a pris à l'école comme un laboratoire de recherche scientifique où l'étudiant a dû subir des examens physiques et psychologiques.

Mots-clés: Pédagogie scientifique.Écoles normales. Manuels scolaires.

\section{UM MÉdico ITALIANO PARA A ESCOLA REPUBLICANA PAULISTA: A PEDAGOGIA CIENTIFICA NAS ESCOLAS NORMAIS BRASILEIRAS}

A antiga Escola Normal de Campinas, que se iniciou em 1903 como Escola Complementar, desde o seu início esteve articulada ao movimento da escola republicana paulista. A escola obteve em seu percurso várias denominações que a colocaram no quadro desse movimento inicial da República e aquele que o seguiu. O compartilhar desse quadro exigiu também que fosse portadora de mobiliário e material de ensino adequados aos ditames da época. Neste texto nos deteremos sobre dois livros que se encontram no acervo bibliográfico da biblioteca histórica da instituição, que compõe o seu arquivo histórico, e que trazem o carimbo da Escola Normal Primária, denominação que a Escola manteve de 1911 a 1920.

O ano de 1911 marcou a reforma da formação docente, com a conversão da Escola Complementar em Escola normal Primária e a conversão da Escola Normal em Normal Secundária, atendendo a incorporação de disciplinas pedagógicas no curso normal primário e a ampliação das referidas disciplinas no currículo do curso normal secundário. As escolas normais primárias passaram a ter o objetivo de habilitar docentes para o exercício profissional nas escolas preliminares - tendo sido incluída a disciplina de pedagogia no currículo do segundo e terceiro anos e a disciplina de pedagogia e educação cívica no quarto ano. 
No caso da Escola Normal Primária de Campinas dentre os materiais que compuseram o seu quadro de itens materiais, importantes ao alinhamento desta instituição às demais que como ela representavam a almejada educação do período, encontra-se o acervo bibliográfico composto por revistas e manuais de ensino, entre outros itens ilustrativos daquela educação. O projeto "Patrimônio Histórico Educativo: A Biblioteca da Escola Normal de Campinas", sob a coordenação de Maria Cristina Menezes, FE/UNICAMP, no âmbito do CIVILIS, Grupo de Estudos e Pesquisa em História da Educação, Cultura Escolar e Cidadania, detém-se sobre a recuperação desta biblioteca que se encontra no edifício posteriormente construído para abrigar definitivamente a instituição, que já então se denominava Escola Normal de Campinas e hospedava outras modalidades de ensino, o que ocasionou o alargamento do acervo bibliográfico em número e título de obras. No trabalho de mapeamento dos itens recuperados, do que restou desta biblioteca, talvez "bibliotecas", uma vez que o movimento de expansão e adensamento da instituição, com proliferação de cursos, disciplinas, períodos de funcionamento, multiplicidade de profissionais habilitados, reflete no movimento e na organização da biblioteca e do acervo por ela acumulado nos vários anos de funcionamento, fazendo dessa única biblioteca, várias bibliotecas (MENEZES, 2016).

\section{DOIS LIVROS QUE CIRCULARAM NAS BIBLIOTECAS DAS ESCOLAS NORMAIS PAULISTAS}

Neste texto, buscaremos trazer dois livros, da biblioteca da antiga Escola Normal de Campinas, registrados com o carimbo da Escola Normal Primária de Campinas e que chamaram a atenção por trazerem ambos o nome do Dr. Ugo Pizzoli, médico italiano que em 1914 ministrou o Curso de Technica Psychologica no Gabinete de Psychologia e Anthropologia Pedagógica annexo à Escola Normal de São Paulo.

Da Itália se origina o primeiro livro, Trattato de Medicina Sociale, obra sob a direção de A. Tamburini, no Tomo: Sanitá Psichica, de subtítulo Pedagogia Científica, o autor é o Dr. Ugo Pizzoli cujo prefácio data de 1909. O livro tem carimbo da Escola Normal Primária de Campinas, que funcionou de 1911 a 1920, período que configura a aquisição deste volume e também período em que a instituição passou de Escola Complementar a Escola Normal Primária, tal como já explicitado.

Publicado no Brasil, o segundo livro 'O Laboratório de Pedagogia Experimental', de 1914, apresenta os textos escritos pelos alunos que seguiram o Curso de Technica Psychologica e utilizaram os aparelhos criados pelo médico italiano Ugo Pizzoli, adquiridos 
para compor o Laboratório de Pedagogia Experimental da Escola Normal de São Paulo. O livro, que conta com o artigo inaugural "O futuro da Pedagogia é Scientífico" do Diretor da Instituição, Oscar Thompson, traz nas páginas finais um modelo de carteira biográfica escolar, a descrição do Gabinete de Anthropologia e Psychologia Pedagógica e é ilustrado com fotos dos aparelhos Pizzoli. A apresentação da carteira biográfica escolar é precedida por uma página de Advertências, na qual consta que os dados anamnesticos da família e do aluno seriam de responsabilidade do médico escolar. A carteira deveria ser conservada pela direção escolar e ser entregue ao governo quando o aluno concluísse o curso.

Estes volumes, seguidos de outros títulos, representam período em que predominou preocupação com a inserção da pedagogia científica, que se articulava à psicologia e à antropologia, no cenário educacional do estado de São Paulo, no Brasil.

O trabalho busca entender a difusão de princípios dessa pedagogia que via a escola como laboratório de investigação científica, na qual o aluno deveria ser submetido a exames físicos e psíquicos, no quadro educacional brasileiro, em especial, na educação paulista.

\section{NA ITALIA}

O livro de Ugo Pizzoli, Pedagogia scientifica, foi publicado na Itália, no âmbito do Trattato di medicina sociale - Sanità Psichica. Obra dividida em duas partes: I- Sanità Fisica e II- Sanità Psichica, sob a direção de Angelo Celli e Augusto Tamburini. 
Figura 1: Folha de rosto do livro Pedagogia scientifica.

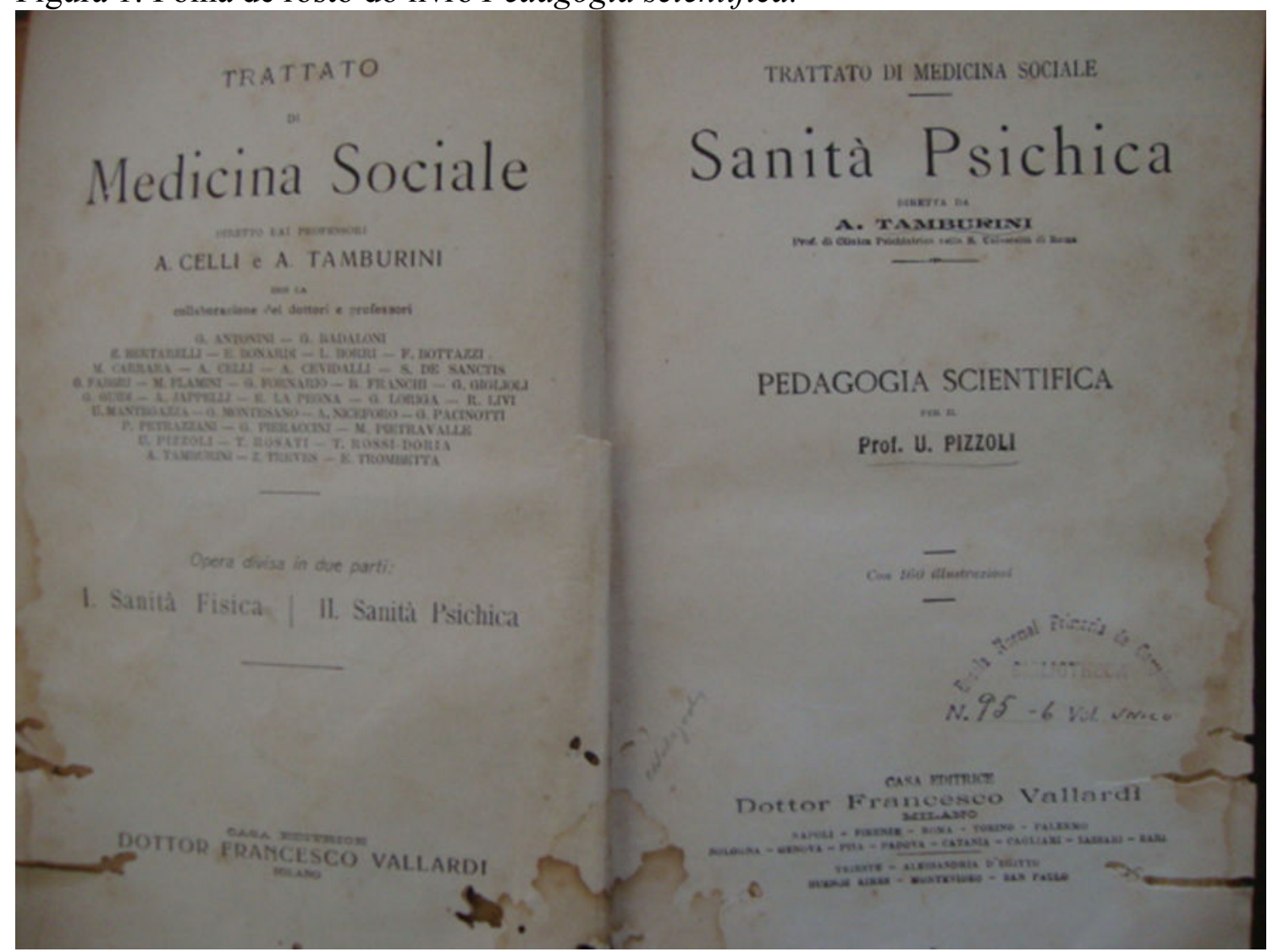

Fonte: Pedagogia Scientifica, 1909.

- Livro: O Dr. Ugo Pizzoli no prefácio do livro, datado de 1909, afirma que a grande corrente do pensamento moderno, no campo da pedagogia, se revigora com o novo elemento da ciência biológica, com o nome de Pedagogia científica. Acrescenta ainda que essa não parte da premissa filosófica, mas diretamente de ciências voltadas para o homem e que vão da biologia à sociologia. Considera impróprio chamá-la de pedagogia científica e que, portanto, chamará de pedagogia que se baseia na biologia. Desta forma anuncia que no breve volume se limitará a expor alguma nota de biologia pedagógica somente (PIZZOLI, 1909, p. VI).

O livro se divide em 04 capítulos precedidos de escrito do autor intitulado 'Noções Gerais' em que discorre sobre a ciência educativa, o educando e apresenta a árvore da biologia pedagógica com as ciências voltadas ao estudo do homem, sob o princípio da arborescência. No centro a Biologia Pedagógica, da qual saltam: a anatomia e fisiologia pedagógica, antropologia pedagógica, psicologia pedagógica, higiene escolar e patologia infantil escolar, que se assenta sobre os conhecimentos científicos seguintes: anatomia humana, fisiologia humana, antropologia, psicologia geral, higiene geral e patologia infantil. 
Esses são os conhecimentos necessários tanto para uma 'educação normal', como para uma 'educação emendativa' (PIZZOLI, 1909. p. 10).

- Noções gerais, tal como se apresenta na figura abaixo:

Figura 2: Árvore da biologia pedagógica.

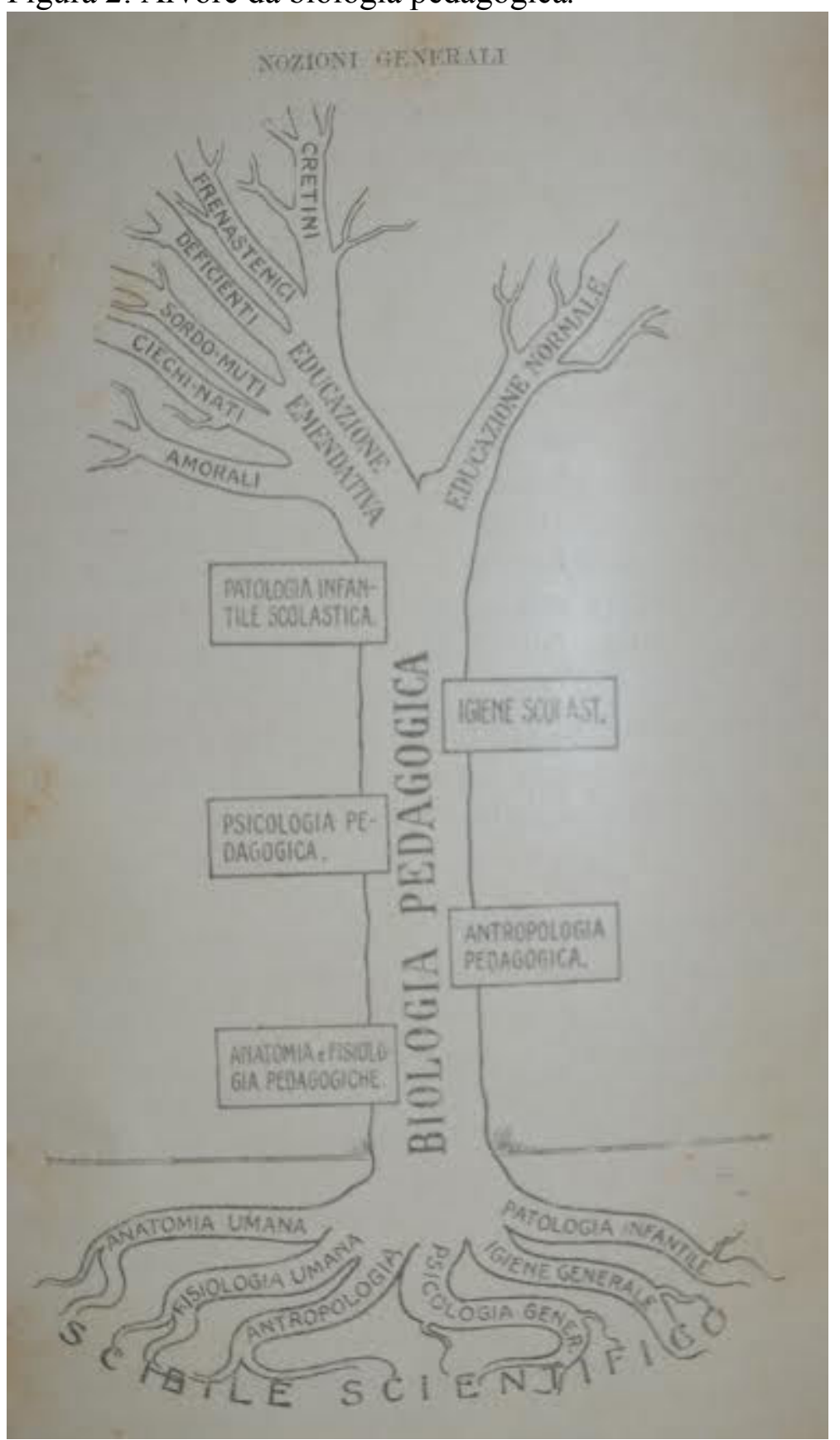

Fonte: Pedagogia Scientifica, 1909.

Os capítulos são compostos pelos temas: 1- Exame anamnestico do educando; 2 Exame somático do educando; 3- Exame fisiopsicológico do educando. Generalidade; 4Juízo em torno do educando. 
Para cada um dos temas são apresentados os itens referentes como, para o 1anamnese da família; do educando; do estado físico. No capítulo 2, para o exame somático apresenta dentre os itens: a testa; a testa e o tipo de nariz, a forma do crânio. O capítulo 3dividido em: A) Exame fisio-psicologico e B) Exame psicológico propriamente dito. Generalidade. No item A aborda a função dos sentidos: sentido do tato, do gosto, da visão, entre outros. Em B: a consciência, a memória, imaginação, entre outros.

Chamou a atenção o fato de todos os capítulos trazerem ao final um modelo de carteira biográfica específica ao tema discutido, tais como:

- Capítulo 1: Carteira biográfica. Exame anamnéstico;

- Capítulo 2: Carteira biográfica. Exame somático;

- Capítulo 3 - Item A: Carteira biográfica. Exame fisio-psicológico e Carteira biográfica. Exame da sensibilidade;

- Capítulo 4: neste capítulo os dois itens arrolados referem-se à carteira biográfica.

- Carteira biográfica. Exame psicológico propriamente dito e Observações para a carteira psicológica Pizzoli.

Ou seja, a carteira biográfica constituiu-se em elemento da maior importância na pedagogia científica de Pizzoli, tal como se apresenta nesta publicação de 1909.

\section{Um laboratório para a escola Italiana}

Já antes, na Itália, em 1899, Pizzoli inaugurara um Laboratório de Pedagogia Científica.

O laboratório tinha por finalidade a preparação técnica dos professores para a realização de exames em seus alunos e, de certa forma, esperava-se que eles promovessem alguma revolução no ensino, aprendendo de forma experimental a avaliá-los. A expectativa era que o professor cientista fosse psicólogo, antropólogo, fisiólogo e higienista. Os cursos de Pedagogia Experimental por ele organizados, segundo Centofanti (2006), se tornaram referência para os educadores italianos.

\section{NO BRASIL}

Enquanto na Itália Pizzoli se encontrava na direção de tentar difundir o movimento do qual a carteira biográfica parecia ser o coroamento, no Brasil, no mesmo período, podemos identificar movimento análogo advindo do Professor primário italiano Clemente Quaglio. Tal 
como Ugo Pizzoli, Quaglio acreditava ser o ambiente escolar local de observações empíricas e de experimentação.

Quaglio irá publicar pequenos textos e proclamar a criação de um laboratório de psicologia, "particular", o que o alçará a membro do grupo dos reformadores da Educação paulista.

O proclamado laboratório tem sua origem em Amparo, de onde Clemente Quaglio, a partir de 1907, dará início às suas publicações na Revista de Ensino, nas quais falará de Pedologia, da necessidade de os professores promoverem experiências em sala de aula, além de também relatar uma experiência que realizou sobre psicologia infantil e, ao que se sabe por ele próprio, “emprega mental tests para avaliar a memória de seus alunos em um grupo escolar, e em um suposto laboratório 'particular"” (CENTOFANTI, 2006, p. 37).

Entretanto, na consideração dos diferentes "suportes" pelos quais as mensagens chegam até os leitores, quando se atenta não só à mensagem em si, mas também à própria materialidade do impresso que lhe serve de suporte, e, ao status que o mesmo goza em determinado período e espaço que lhe conferem importância quando estudado no universo representacional em que se insere, é que se pode entender a força da publicação de Quaglio no Anuário de Ensino de 1910 com o título 'Gabinetes de Antropologia Pedagógica e Psychologia Experimental' (CHARTIER, 2011).

No artigo, Clemente Quaglio diz ser preciso vigiar de perto a criança e para tal anuncia a importância da folha biográfica, na qual deveria constar exame de vista, audição, força muscular, estatura, circunferência torácica, peso, memória e grau de atenção. Para ele, a folha biográfica poderia ser mais extensa e completa se os mestres esforçados e inteligentes desenvolvessem estudos pedológicos e adquirissem os aparelhos necessários, dentre os quais cita alguns do Dr. Pizzoli. Afirmava ainda a importância da folha biográfica ao acompanhar o aluno, quando o mesmo mudasse de escola (QUAGLIO, 1910).

Sobre essa publicação, tal texto, ao ser escrito em impresso de caráter oficial do governo, ganha força no quadro representacional no qual se insere. Nele, Clemente Quaglio apresentará ao professorado um texto considerado por muitos como um marco na história da psicologia de São Paulo, e o primeiro passo na direção do Laboratório de Pedagogia Científica, inclusive, será considerado inovador por ter sido escrito por um autor local. 


\section{UM MÉDICO ITALIANO PARA A ESCOLA PAULISTA}

Para Centofanti, encontrar o italiano Ugo Pizzoli (1863-1934) na origem de um laboratório de psicologia, no início da segunda década do século passado, em escolas normais de São Paulo, sempre foi um elemento destoante na paisagem da história da psicologia no Brasil. Fosse ele francês, belga, austríaco, alemão, suíço ou inglês, e seria mais fácil aos investigadores deduzirem suas orientações e aceitarem seus feitos, uma vez que as psicologias que nos influenciaram falavam francês, alemão e inglês, e formaram o nosso pensamento (CENTOFANTI, 2006).

Do ponto de vista conceitual, o projeto da Pedagogia científica italiana pode ser entendido como um desdobramento do positivismo naquele país, cuja história difere da expressão que teve no Brasil. O positivismo italiano foi um movimento científico, antes de ser um movimento filosófico, e teve o evolucionismo como modelo.

Nesse quadro, Ugo Pizzoli alinhava-se ao pensamento científico advindo dos estudos e escritos realizados em especial por Paolo Mantegazza (1831-1910) e Cesare Lombroso, que como forma de promover a melhoria das condições de vida dos cidadãos tomava por base $o$ princípio da regeneração da raça e buscava mapear o estado físico e mental do italiano médio, buscando encontrar um remédio para esses desvios através de uma educação sanitária elementar, que esperava contar com a atuação dos professores.Os métodos utilizados por Cesare Lombroso para o tal mapeamento foram os da antropologia descritiva, empregados na zoologia, na busca de indícios que permitissem identificar e quantificar os anormais de inteligência e os delinquentes. A crença nas semelhanças entre essas duas categorias levou a defesa da ideia genérica que as perturbações psíquicas vinham acompanhadas de respectivas desordens morfológicas e físicas (CENTOFANTI, 2006).

Segundo o mesmo autor, com o emprego de procedimentos e instrumentos da antropometria e da psicometria, Lombroso classificou alguns segmentos dessas categorias como inferiores, alegando que eles representavam, no presente, estágios passados ao longo da evolução do homem. O Estado não podia, diante do argumento, confiar a sorte de seus cidadãos e de suas relações econômicas, políticas e sociais aos caprichos da seleção natural, uma vez que isso daria oportunidade de sobrevivência apenas aos mais fortes. Era necessário criar mecanismos de seleção artificial, que fossem capazes de garantir condições de sobrevivência também aos mais fracos. Converter a escola em um laboratório era convertê-la em espaço de pesquisa, instrumento de seleção artificial, capaz de investir no desenvolvimento do indivíduo para adequá-lo ao mundo do trabalho (CENTOFANTI, 2006). 
Os professores seriam os sujeitos capazes de atuar na condução dessa missão regeneradora, para tal, era necessário dotá-los de bases científicas para que pudessem trabalhar o desenvolvimento do caráter das crianças, com o suporte de ciências como a antropologia, a psicologia, a fisiologia, a anatomia, a patologia e a higiene, no âmbito das ciências biológicas, e a sociologia na esfera das ciências morais.

\section{COMO ESSA VERTENTE CHEGA AO BRASIL?}

Ao que tudo indica, tal como já exposto neste texto, pode-se ponderar que a Pedagogia científica, articulada ao Projeto Pizzoli, e o próprio Pizzoli, chegaram a São Paulo pelas mãos do imigrante italiano Clemente Quaglio (1872-1948), até então um desconhecido professor primário de uma pequena cidade do interior paulista e que ganha fama após adotar no Brasil os procedimentos utilizados por Pizzoli, na Itália. Esse professor esteve diretamente relacionado à criação do Laboratório de Pedagogia Científica.

Para Centofanti, são tantas as coincidências, que não há como deixar de tomar por hipótese a suspeita de existir entre eles uma comunicação próxima e prolongada.

Pizzoli e Quaglio tinham em comum o espírito prático. O ingresso de Pizzoli no projeto da Pedagogia científica italiana teve como origem pequenos artigos que publicou entre 1893 e 1898, versando sobre assuntos diversos de interesse da educação. Seu diferencial, entretanto, foi ter inaugurado em Crevalcore, Itália, o primeiro laboratório de Pedagogia científica da Itália, em 1899 (CENTOFANTI, 2006).

Com a provável participação de Quaglio, e com o possível assessoramento de Pizzoli, o professor normalista Oscar Thompson (1872-1938), à frente da Diretoria Geral da Instrução Pública, liderou em 1909 um grupo de normalistas que pretendia, segundo Monarcha (1999, p. 245 apud CENTOFANTI, 2006) "integrar a pedagogia, ciência infusa, com outros campos de conhecimento em expansão: psicologia fisiológica, antropologia física e antropometria”. Como reflexo, foi criado o Serviço de Inspeção Médico-Escolar, embora só viesse a se tornar uma prática em 1916, com Thompson novamente no mesmo cargo.

Tavares, sobre os laboratórios em São Paulo, informa:

[...] no estado de S. Paulo, a notícia mais remota que se tem de laboratórios desse tipo, é a de que, em 1908, num pequeno grupo escolar da cidade de Amparo, o professor Clemente QUAGLIO realizava experiências psicométricas com seus alunos, pesquisando fadiga muscular, sensibilidade auditiva e visual, tempo de reação e memória de aprendizagem (QUAGLIO, 1908).

Talvez pelo interesse despertado por suas pesquisas, cujos resultados foram publicados na Revista do Ensino, o fato é que QUAGLIO, durante a gestão de Oscar 
THOMPSON na Diretoria Geral da Instrução Pública passou a ser responsável, a partir de 1911, do "Gabinete de Psicologia Experimental" da Escola Normal de São Paulo, atual "Caetano de Campos". De suas novas atividades nesse gabinete, também pouco se sabe, pois não encontramos mais indícios de suas possíveis publicações. Mas é de se crer que a reputação do Gabinete de Psicologia Experimental tenha aumentado com o passar dos anos, ou então que se tenha sentido a importância em reformular sua estrutura e objetivos, pois, já em 1914, o governo do estado decide por fazer maiores investimentos nessa área, contratando, pelo prazo de um ano, o "psicologista" italiano Ugo PIZZOLI. Segundo notícias publicadas pelo próprio Gabinete, "após um anno de trabalho exhaustivo, o Prof. PIZZOLI conseguiu apresentar um gabinete montado com parcimonia mas com todos os apparelhos necessarios para as experiencias mais importantes de psychologia experimental. Além do trabalho de organização, em que empregava grande parte do dia, encarregava-se o Prof. PIZZOLI de um curso de pedagogia scientifica, destinado especialmente aos professores de pedagogia, inspectores escolares e directores de grupo" (ESCOLA NORMAL DE SÃO PAULO, 1927:3).O Gabinete de Psicologia Experimental servia a três finalidades básicas: ser o local de demonstração das descobertas e leis da moderna psicometria, para os alunos da escola normal; oferecer, aos professores de outras escolas, cursos de atualização em "pedagogia científica", e, finalmente, ser o instrumento de classificação psicoantropométrica dos alunos da escola modelo, os quais, a partir dessa data, passariam a ter um ficha especial para seu acompanhento escolar. (TAVARES, 1994, p. 5).

Em 1911, Quaglio publica um pequeno livro, também com ineditismo em São Paulo igualmente pelo fato de ser de autor local: Compêndio de Pedologia, com o aviso de ser um guia prático para a execução da folha biográfica nas escolas primárias. Mais do que antes, na condição de receituário, trazia agora a inclusão de um modelo de folha biográfica. (CENTOFANTI, 2006, p. 9).

\section{UM GABINETE ANTROPOLOGIA PEDAGógICA E PSICOLOGIA EXPERIMENTAL}

Os meios vieram logo a seguir. Promoveu-se mudança na organização curricular de 1912 e, como consequência, foi criada a cadeira de psicologia experimental.

Articulado a essa cadeira cria-se também o Gabinete de Antropologia Pedagógica e Psicologia Experimental que ficará sob a responsabilidade de Clemente Quaglio, que irá ministrar aulas teóricas e exercícios práticos. Além da capital, a cadeira é também instituída no currículo das escolas normais secundárias recém criadas em Itapetininga e São Carlos, o que representa a chegada dos laboratórios ao interior paulista.

Para Tavares, pode-se considerar mesmo que o convite formulado pelo governo do estado de São Paulo, em 1913, para que Ugo Pizzoli aceitasse a estada no laboratório da escola da capital em 1914, deveu-se em parte às dificuldades operacionais geradas pela 
condição do "autodidatismo" dos "recém-inventados" professores de psicologia experimental e seus respectivos encarregados de laboratório (TAVARES, 1994).

Em nova nota esclarece Centofanti (2006), o quanto a educação dos sentidos torna-se essencial para o desenvolvimento intelectual do indivíduo. A coincidência dessa psicologia com fenômenos privilegiados pela investigação em laboratórios no final do século XIX e início do século $\mathrm{XX}$, facilitou aos antropólogos e psicólogos de matriz evolucionista o emprego de aparelhos e instrumentos dos laboratórios para avaliação física e mental dos indivíduos na perspectiva da aplicação, inclusive como recursos para educação dos sentidos.

Desta forma, a escola paulista em 1914, com a vinda do Dr. Pizzoli à Escola Normal de São Paulo, vai inaugurar o Gabinete de Psicologia Experimental, no qual Pizzoli ministrará Curso com a utilização dos aparelhos que se instalam, tal curso resultará na publicação do $2^{\circ}$ livro que nos propusemos a apresentar.

Figura 3: Gabinete de Anthropologia Pedagógica. Material didactico demonstrativo e instrumentos para medidas anthtopometricas.

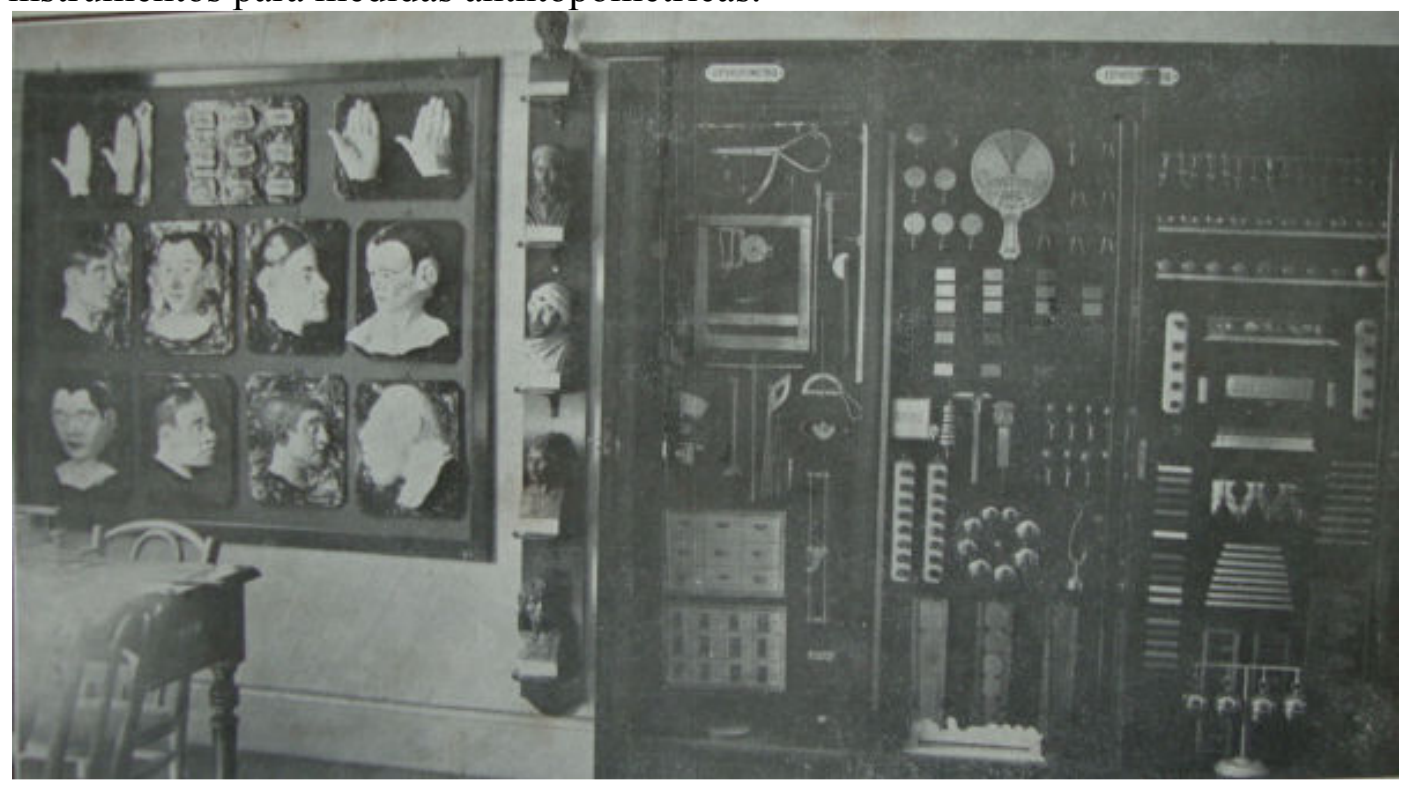

Fonte:O laboratório de Pedagogia Experimental, 1914.

\section{O LABORATÓRIO NO BRASIL}

$2^{\mathrm{o}}$ momento - Livro organizado no Brasil

$2^{\circ}$ livro: O laboratório de Pedagogia Experimental:

- Organizado, orientado e apresentado pelo próprio Pizzoli, o livro traz as teses desenvolvidas pelos professores que seguiram o curso de Thecnica Psicologica, ministrado pelo Dr. 
Pizzoli de 15 de junho a 15 de julho de 1914, destinado especialmente aos professores de Pedagogia, inspetores escolares e diretores de grupos escolares.

A publicação, após breve apresentação de Ugo Pizzoli, se inicia com o texto de Oscar Thompson, Director da Escola Normal de São Paulo, "O futuro da Pedagogia é científico". Em seguida, Ruy de Paula Souza, Adalgiso Pereira, Carlos Alberto Gomes Cardim, Roldão Lopes de Barros, Clemente Quaglio, Saverio Cristofaro e Joaquim A. de Sant'Anna, apresentam os textos de suas teses.

- O último texto intitulado: Relatório sobre o "Curso de Cultura Pedagógica", professado perante os professores de Pedagogia, inspetores escolares e Diretores de Grupos pelo Dr. Pizzoli é direcionado ao então Secretário de Estado dos Negócios do Interior. Neste texto Ugo Pizzoli expõe o programa do curso oferecido, composto por quarenta e seis lições teórico-práticas, e apresenta a relação dos professores, inspetores e diretores escolares, que o havia frequentado, esclarece que os inscritos foram 52, mas por motivos justificados apenas 34 puderam frequentar o curso assiduamente e traz os nomes dos frequentes. Refere-se ao curso ministrado como Curso de Pedagogia Científica, não mais como Curso de Thecnica Psicológica, como em sua apresentação.

Como na $1^{\mathrm{a}}$ publicação apresentada, o texto traz ao final o modelo da Carteira Biográfica Pizzoli, não sem antes estampar uma foto do Professor rodeado por aqueles que frequentaram o seu curso.

A página de abertura da carteira, antes do título "Carteira Biográfica Escolar", vem encabeçada por "Estado de São Paulo". Os itens para preenchimento são: No, nome do aluno, nome do Grupo Escolar, data de início e data de término do preenchimento da Carteira. $\mathrm{Na}$ página seguinte se lê: "Advertências", nas quais se afirma a importância depositada na carteira. Nesta página se adverte que a carteira será usada durante todo o curso preliminar e deve ser cuidadosamente conservada pelo Diretor do Grupo Escolar, que a entregará ao governo assim que o aluno terminar o curso.

As advertências prosseguem sobre as demais páginas de preenchimento que assim são organizadas:

A - Notas Geraes, constam os informes pessoais do aluno, se adverte que devem ser tomadas pelo Diretor do estabelecimento e consta abaixo local para assinatura do Diretor;

B - Dados Anamnesticos, com questões diretas sobre estado físico, estado moral e condições sociais da família, a página também deverá ser assinada pelo diretor, entretanto, serão tomadas pelo diretor e pelo médico; 
C - Notas Anamnesticas (Exame Físico do Aluno), referem-se à saúde do aluno, moléstias sofridas, o controle dos exames médicos realizados com a data e as observações médicas do estado de saúde do mesmo pelo médico. A página deveria ser assinada apenas pelo médico; D - Observações Anthropológicas, preenchidas e assinadas pelo Professor;

E - Observações Physio-psychológicas ao encargo do professor da classe, que assinará estas páginas;

Página final: dividida em 04 quadros e intitulada: Photographias do alumno.

Figura 4: Folha de rosto do livro "O Laboratório".

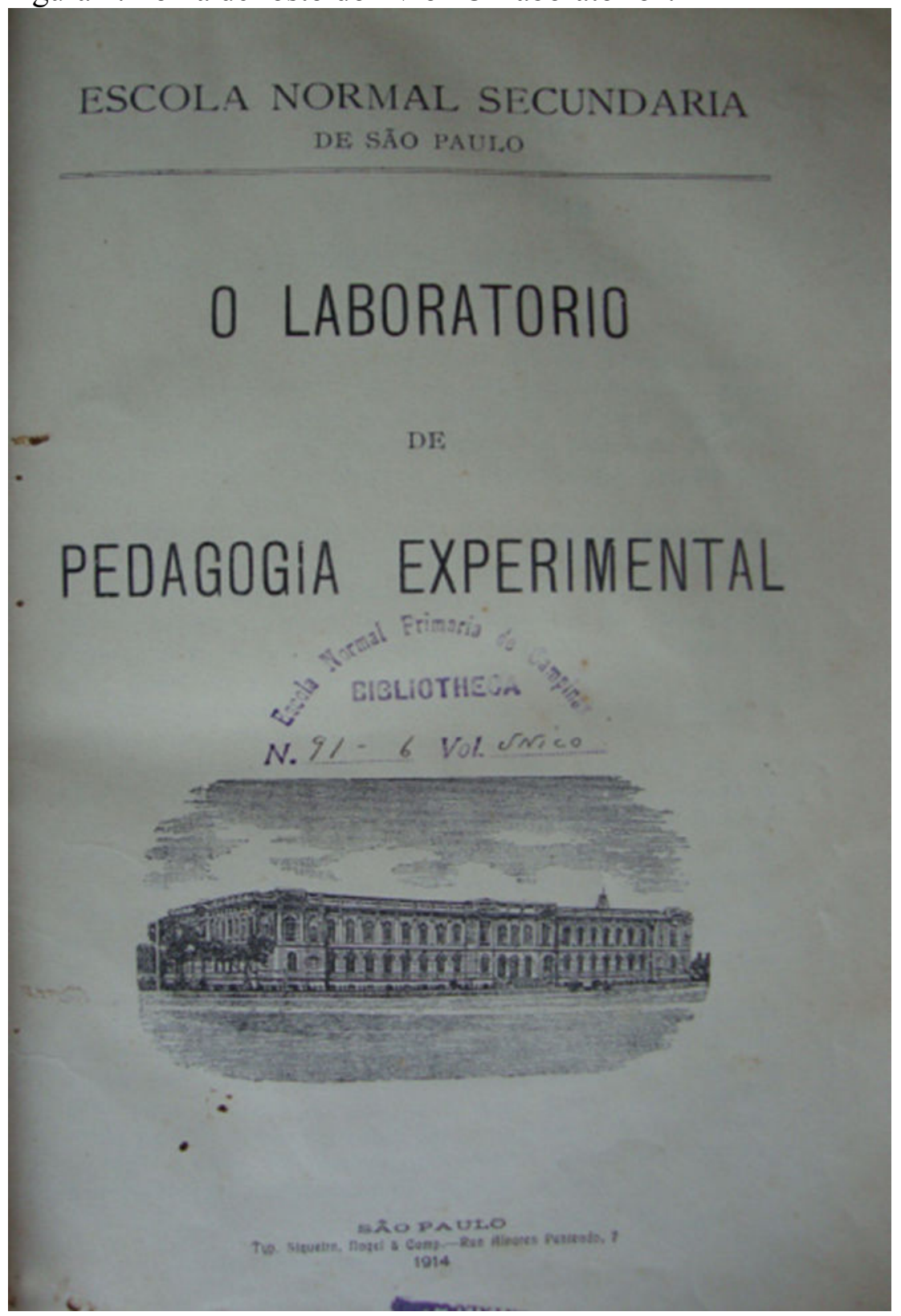

Fonte:O laboratório de Pedagogia Experimental, 1914. 
Figura 5: Experiência realizada pelo Prof. Clemente Quaglio durante o curso de Pedagogia Científica do Dr. Ugo Pizzoli.

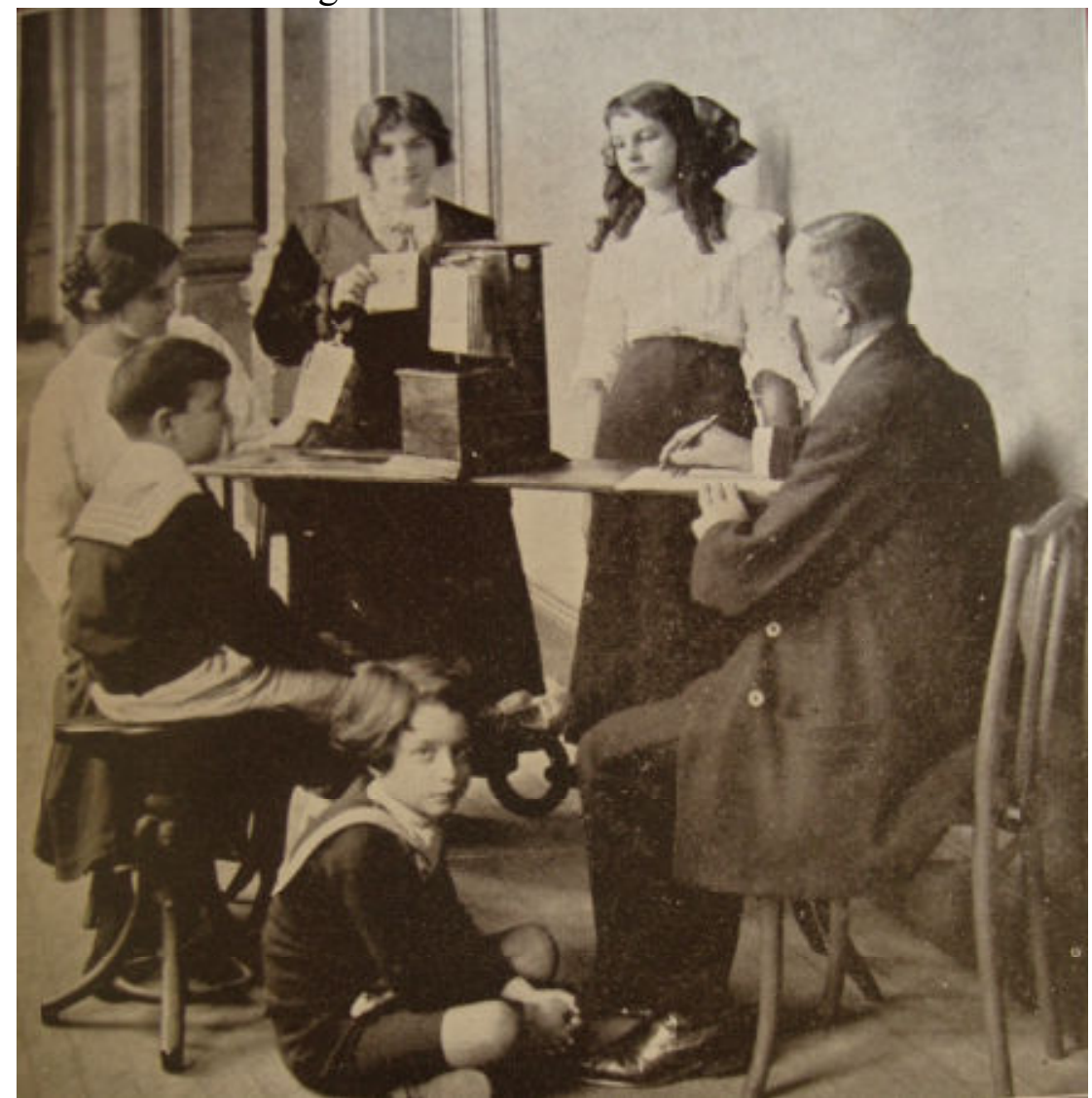

Fonte: O laboratório de Pedagogia Experimental, 1914.

\section{A CARTEIRA BIOGRAFICA DO DR PIZZOLI: ORIGEM DE UM INSTRUMENTO}

Em 1885, na Itália, Giuseppe Sergi havia sugerido que se recolhessem nas escolas os dados elementares que poderiam servir de base à pedagogia científica, por meio de observações a serem registradas em um prontuário, ao qual deu o nome de folha biográfica. Para encontrar os métodos naturais que seriam os parâmetros da nova pedagogia, Sergi dizia que seriam necessárias numerosas observações exatas e racionais para precisar as condições físicas e psíquicas em que se encontrava o educando, nos vários períodos de vida. A folha biográfica permitiria o registro das diferenças individuais, condição pouco observada pelos educadores, que tratavam "as crianças como se fossem todas iguais, como se pensassem e sentissem igualmente, como se tivessem a mesma força física e intelectiva, e a mesma força emocional" (CENTOFANTI, 2006, p. 109).

Como forma de promover a melhoria das condições de vida dos cidadãos, tomou-se por base o princípio da regeneração da raça, e, por intermédio de pesquisas realizadas por Paolo Mantegazza (1831-1910) e Cesare Lombroso (1835-1909), procurou-se mapear o 
estado físico e mental do italiano médioe, ao mesmo tempo, por intermédio dos professores, buscou-se encontrar um remédio para esses desvios através de uma educação sanitária elementar.

\section{UM INSTRUMENTO QUE PERSISTE AINDA EM 1918}

A crença na carteira e nas possibilidades por ela abertas, pelo controle vislumbrado, parece ter persistido no cenário educacional brasileiro. Talvez fosse mesmo falta de outras possibilidades mais imediatas.

Em 1918, o Secretário do Interior "Dr. Oscar Rodrigues Alves" ao visitar as Escolas Normais do Braz, na capital, em Campinas, Piracicaba e Pirassununga e suas escolas anexas, se depara com as queixas dos professores para o desenvolvimento do ensino nas disciplinas de psicologia aplicada à educação, pedagogia e metodologia.

A Escola Normal tinha como missão formar bons professores para que o funcionamento do ensino primário fosse de qualidade, entretanto, as condições desfavoráveis, tal como já haviam se expressado os mestres impedia o bom funcionamento do ensino. Só poderia haver uma boa formação se se garantisse que as escolas normais proporcionassem aos alunos as condições para observar, ensinar e acompanhar os programas de ensino nas escolas modelos.

As orientações do Secretário do Interior "Dr. Oscar Rodrigues Alves", para que se pudesse garantir o bom funcionamento da prática de ensino, versavam sobre a necessidade de um corpo docente qualificado nas escolas modelos, maior atenção do lente de Pedagogia na questão do método, sobretudo orientado à prática de ensino, além da necessidade de colocar uma aula prática por semana no $2^{\circ}$ ano. "Os alumnos deverão assistir a aulas-modelo, nas classes da escola-modelo, onde farão, exclusivamente, exercícios de observação, familiarizando-se com tudo quanto diz respeito á parte material da escola e do ensino primário" (ANUÁRIO, 1918, p. 287).

Nas aulas da cadeira de Pedagogia seriam definidos os temas que seriam observados na escola modelo: "a) à disciplina, em geral; b) ao material didactico usado em cada anno do curso; c) aos livros adoptados; d) à hygiene; e) à escripturação". Após esses itens observados, essas informações permitiriam conhecer o meio escolar antes de começar a prática de ensino. Após a observação, o aluno deveria entregar um relatório ao Lente de Pedagogia que faria uma crítica sobre as falhas da observação. 
Para a prática de ensino, era importante a preparação pedagógica com aulas figuradas e ida dos alunos da escola modelo à sala do $4^{\circ}$ ano para ser dada aula por um praticante. "Uma prática de ensino de observação viva offerece sempre oportunidades de os professores experimentados e de boa vontade applicarem a critica pedagógica, poderoso elemento de educação, cujas vantagens são indiscutíveis.” (ANUÁRIO, 1918, p. 289).

Além dessas medidas, se recomendava que os alunos-mestres visitassem as classes das escolas modelo, com o Lente de Pedagogia, as visitas se realizariam nas últimas semanas de março, maio, julho, setembro, outubro e novembro, podendo o praticante dar aulas com orientação e preparo prévios.

Ainda se anuncia, no texto do Anuário de Ensino de 1918, que a título de experiência, se enviaria a todos os diretores de escolas normais o processo empregado em Modena, Itália, nas aulas de metodologia prática, pelo professor Ugo Pizzoli. O modelo da carteira se publica em seguida, nessa mesma página do Anuário. Tal como mostramos abaixo. Carteira derivada das folhas inicialmente propostas por Sergi, desenvolvida por Pizzoli, cultuada no Brasil, quando publicada sob os auspícios do Governo do Estado. Reaparece no Anuário de 1918, para se acompanhar a prática dos alunos das escolas normais, que seriam avaliados pelo Cathedrático de Pedagogia. Parece que dela ainda se esperava muito. 
Figura 6: Modelo de carteira utilizado pelo Dr. Pizzoli, na Itália, nas aulas de Metodologia Prática e publicado no Anuário de Ensino de 1918, para que fosse utilizada pelos Catedráticos de Pedagogia das Escolas Normais Paulistas.

A titulo de experiencia, enviamos a todos os directores de escolas normaes o processo empregado em Modena, Italia, nas aulas de methodologia pratica, pelo professor Hugo Pizzoli.

Consiste esse processo nas indicações do quadro abaixo.

Notas do Cathedratico de Pedagogia

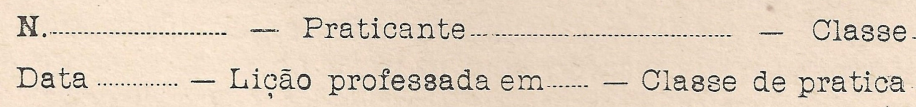

Fonte: Anuário de Ensino, 1918, p. 01 da carteira.

\section{CONSIDERAÇÕES INICIAIS E PROVISÓRIAS}

Resta-nos saber se foram de fato preenchidas a tão valorizadas carteiras biográficas, folhas e notas escolares e se tiveram a importância que delas se aguardava no ordinário das práticas institucionais. Delas não temos notícias ao nos debruçarmos sobre a documentação escolar, não tivemos acesso nunca a tal documentação, como pudemos obter de outras, tais como os prontuários e outros documentos institucionais que se referem a alunos e mestres.

Quem sabe ainda em alguma gaveta esquecida de um velho arquivo. Por enquanto, apenas os indícios em velhas publicações corroídas pelo tempo, nas prateleiras de depósitos dos quais buscamos recuperar as bibliotecas que compõem os arquivos "mortos", que buscamos ressuscitar. Vestígios deixados às traças, coletados e agregados a outros pormenores, vistos ainda, não raras vezes, como insignificantes para o entendimento das histórias a serem reconstruídas em nossas instituições (GINZBURG, 1989). 


\section{REFERÊNCIAS}

CENTOFANTI, R. Ugo Pizzoli. Estudos e Pesquisas em Psicologia, ano 2, n. 1, p. 75-93. 2006.

CHARTIER, R. Defesa e ilustração da noção de representação. Fronteiras, Dourados, MS, v. 13, n. 23, p. 15-29, jan./jun. 2011.

ESCOLA NORMAL SECUNDÁRIA DE SÃO PAULO. O Laboratório de Pedagogia Experimental. São Paulo, Typ. Siqueira, Nagel \& Comp., 1914.

GINZBURG, C. Mitos, Emblemas, Sinais: morfologia e história. São Paulo: Cia das Letras, 1989.

QUAGLIO, C. Gabinetes de anthropologia pedagogica e psychologia experimental. In: SÃO PAULO (Estado). Annuario do Ensino do Estado de São Paulo: 1909-1910. Typografia do Diario Official, 1910, p. 162-166.

MENEZES, M. C. Projetar espaços visando a organização e a difusão da cultura material escolar: Diálogo entre acervos. In: MENEZES, M. C. (org.) Desafios Iberoamericanos: O Patrimônio Histórico-Educativo em Rede. Campinas: CIVILIS/UNICAMP - RIDPHE CME/USP, 2016. (Coleção Patrimônio Histórico Educativo).

PIZZOLI, U. Pedagogia scientifica. Milano: Casa Editrice: Dottor Francesco Vallardi, 1909. (Trattato di Medicina Sociale - Sanità Psichica diretta da A. Tamburini, Professore di Clinica Psichiatrica nella Università di Roma).

. Relatório sobre o curso de cultura pedagógica. In: O laboratório de Pedagogia Experimental. São Paulo, Typ. Siqueira, Nagel \& Comp., 1914, p. 137-143.

SÃO PAULO (Estado). Annuario do Ensino do Estado de São Paulo. São Paulo, 1918.

TAVARES, A. F. R. A Psicologia e a formação do sistema público de ensino no Estado de S. Paulo. In: Anais do I Simpósio de Pesquisa da FEUSP. SP: FEUSP, Série Estudos e Documentos, v. 31, 1994. 